\title{
Aportes de la pedagogía crítica a la fundamentación metodológica de la teología de la liberación en América Latina ${ }^{1}$
}

\author{
Contributions of the critical pedagogy to the Theology of \\ the Liberation's methodological ground in Latin America
}

Resumen

Este artículo muestra las características generales que representan la labor de la teología de la liberación y de la pedagogía crítica, que identifican su surgimiento histórico, dimensiona el alcance y labor desarrollada en pro de la liberación y, evidencia, el punto en común entre estas dos disciplinas, para proponer unos elementos que fungen como base para las elaboraciones metodológicas de la teología de la liberación.

Palabras clave: Pedagogía crítica; Teología de la liberación; Método de la teología.
John Jairo Pérez Vargas ${ }^{2}$

Yuliana Andrea González Arcila ${ }^{3}$ Angélica Natali Rodríguez Robayo ${ }^{4}$

\footnotetext{
${ }^{1}$ Resultado de investigación correspondiente al Semillero de Investigación Teología y Sociedad, adscrito al Programa de Licenciatura en Teología de la Facultad de Educación, convocatoria de 2016 - Universidad Santo Tomás.

${ }^{2}$ Licenciado en Teología Pontificia Universidad Javeriana. Especialista. Magíster en Bioética de la Universidad del Bosque. Investigador en metaética, pedagogía y teología. Docente tiempo completo Universidad Santo Tomás, coordinador del semillero Teología y Sociedad. E-mail: johnperezv@ustadistancia.edu.co - johnjapeva@gmail.com

${ }^{3}$ Estudiante de Licenciatura en Teología VI semestre. Religiosa de la comunidad Dominicas Hijas de Nuestra Señora de Nazareth, integrante del semillero Teología y Sociedad. Email: yulianagonzalez@ustadistancia.edu.co

${ }^{4}$ Religiosa de la comunidad de Dominicas Hijas de Nuestra Señora de Nazareth, estudiante de IX Semestre de la Licenciatura en Teología en la Universidad Santo Tomás, integrante del semillero de investigación Teología y Sociedad. E-mail: angelicarodriguezr@ustadistancia.edu.co
} 


\section{Introducción}

La teología de la liberación es una nueva manera de hacer teología, surge esencialmente en Europa y se potenciada en gran medida en el contexto latinoamericano, igual sucede con la pedagogía crítica, pues es en Latinoamérica donde surgen varios teóricos que dan sustento a estas corrientes. En este texto se plantea la necesidad de identificar algunos rasgos particulares de cada una de estas corrientes, su desarrollo histórico y su concreción práctica para fundamentar epistemológicamente un método para la teología de la liberación.

Se caracteriza la teología de la liberación y la pedagogía crítica y se destacan sus afinidades y divergencias para dimensionar los aportes de la pedagogía crítica a la teología de la liberación.

Se proponen unas categorías eje que reflejan los fundamentos epistemológicos de la metodología de la liberación abordada desde la teología y que son apoyadas con elementos propios de la pedagogía crítica.

Más que un método se proponen unos elementos subyacentes a las comprensiones metodológicas que se soportan en una articulación entre pedagogía crítica y teología de la liberación que tiene como fin promover procesos emancipatorios promovidos desde distintos campos de comprensión y que a la postre resultan afines y complementarios.

\section{Desarrollo}

Una de las grandes transformaciones de la historia de la humanidad surge del movimiento Europeo que emerge de la escuela de Frankfurt, donde exponentes como Habermas propone, por medio de la teoría de las intencionalidades, tres grandes enfoques alrededor de las ciencias y las clasifica en tres ejes de comprensión: las empírico naturales, las hermenéuticas y las ciencias socio-críticas; en las dos primeras no incluyen entre sus presupuestos el interés emancipatorio pues éste solo es logrado gracias a la reflexión crítica (Alútiz, 2010, p. 86). Es así que la teología como se venía configurando tradicionalmente se comprende como una ciencia hermenéutica; a partir de la década de los 60, gracias a la teología de la liberación emerge como una reflexión crítica de la praxis histórica, (...) que no se limita a pensar el mundo, sino que busca situarse como un momento del proceso a través del cual el mundo es transformado (...) en la construcción de una nueva sociedad, justa y fraternal. (Gutiérrez, 1975, pp. 40-41), adquiriendo así un carácter de corte socio-crítico.

Lo anterior debido a que se basa en un proceso de liberación emergente de la realidad, el cual "ve y actúa desde los oprimidos y en contra de su opresión, a favor de los pobres y en contra de su empobrecimiento" (Boff, 1984, p. 23). Es por tanto que, la teología de la liberación se fundamenta en un método que analiza y estudia la realidad viva de los pueblos latinoamericanos y sus comunidades a la luz de la revelación de Jesús en atención a la viva realidad (Ellacuría, 1984, p. 154), lo cual conlleva a percibir la fe como aquella que trasciende e interpela la praxis evangélica en relación al compromiso cristiano, desde los escenarios de injusticia, opresión, marginación, exclusión, entre otros y lleva a reconstruir y dignificar su vida desde el anuncio salvífico del Evangelio.

No obstante, para poder llegar a estos fundamentos, la teología de la liberación ha pasado por distintos procesos históricos que la llevan a caracterizarse por ofrecer, desde una perspectiva analógica, una nueva lectura del Evangelio y aproximación crítica que toma algunos elementos de corte marxista en torno a la relación teoría y praxis leídos e interpretados de manera contextual y aplicados de manera coherente a las proposiciones evangélicas. De esta manera, la teología de la liberación, según lo plantea Suárez (2007), ubica 
sus raíces desde el comienzo de la colonización, donde los primeros misioneros y evangelizadores cuestionaron notablemente la manera como la Iglesia hacía presencia en el continente; al igual que la forma como eran tratados los indígenas, los negros, los mestizos y las poblaciones pobres del campo y de la ciudad, es así que se percibe desde el mismo colonialismo raíces que se convertirán posteriormente en necesidad y posibilidad de acción de la teología de la liberación.

En épocas más recientes, para dar respuesta a la necesidad de una presencia eclesial más activa, desde el Concilio Vaticano II (1965) se analiza y evalúa la misión evangelizadora en los diversos ámbitos pastorales, a la luz del impacto transformador del anuncio evangélico, en dichas realidades de opresión y marginación. Así mismo, la Conferencia General del Episcopado Latinoamericano y del Caribe, celebrada en Medellín (1968) resalta la necesidad de la evangelización y maduración de la fe, a través de los actos de piedad y la praxis evangélica, teniendo en cuenta los problemas de la comunidad y la necesidad de una liberación en búsqueda de la promoción humana, el desarrollo de los pueblos y la renovación eclesial.

En su desarrollo histórico, la teología de la liberación propone, tal vez, no tanto un nuevo tema para la reflexión, cuanto una nueva manera de hacer teología (Gutiérrez, 1975, p. 40), es decir se plantea lo que significa hacer presencia activa en la historia desde la situación de pobreza, opresión, marginación y exclusión; tornándose como lugares privilegiados desde los cuales diversos teólogos latinoamericanos han plasmado sus pensamientos y reflexiones críticas con argumentos de carácter liberador; es así que la intención de los teólogos de la liberación, al hacer teología es la de proclamar y vivir el Evangelio desde la percepción histórica de la realidad de pobreza y opresión movidos por la fe.

Donde dicha fe leída en el contexto de la teología de la liberación se ha visto acompañada según la perspectiva crítica de Ellacuría (1984) por el carácter dialéctico de la pobreza y su carácter político (p. 155) es decir, que en la pobreza se halla la posibilidad de un despertar a una nueva realidad: la de los pobres y víctimas, producto del pecado y de la opresión humana, lo cual trasciende todo: vida religiosa y eclesial, intereses intelectuales, fe y dudas de fe, como preguntas teológicas (Sobrino, 2001 , p. 616). Es por tanto, que los fundamentos que se plantean en la teología de la liberación dan lugar a la esperanza, la dignidad, la solidaridad, en la incesante búsqueda de sentido y plenitud existencial, desde la reconstrucción y dignificación de la vida humana lo que se configura en una posibilidad de actuación política que se caracteriza por la búsqueda de la justicia, igualdad, dignificación y libertad, no solo física sino que adquirirán ante todo un sentido espiritual, que sea signo de apertura y compromiso de la Iglesia en el mundo, lo que implica una ruptura con el modo de ver y de actuar que es habitual en la sociedad y en la Iglesia (Boff, 1984, p. 23), "favoreciendo un compromiso de solidaridad con los que sufren" (CELAM, 1968, p. 102).

De manera similar, la teología de la liberación que busca dar respuesta a las necesidades y sufrimientos de los pueblos latinoamericanos en sus contextos de injusticia, desigualdad social, pobreza, dominación y opresión, se puede asociar, en el ámbito educativo y social, a una apuesta pedagógica de carácter crítico que en específico emerge de la lectura de la realidad latinoamericana y sus problemas sociales, educativos, políticos y económicos imperantes y encuentra oportunidad de acción gracias a la educación popular y al trabajo alrededor de las comunidades y recibe influencia de las ideas europeas en relación a la Escuela de Frankfurt relacionadas con el desarrollo de pensamiento crítico, la emancipación, la libertad, entre otros aspectos. 
Es importante anotar que esta corriente pedagógica es desarrollada en Latinoamérica, principalmente, por Freire (s.f), pedagogo brasileño, quien en los años 60 surge como un movimiento educativo crítico denominado Pedagogía del oprimido, que propone la educación como posibilidad de liberación desde la concienciación del oprimido y la lucha por su propia emancipación reconociéndose éste como principal protagonista del proceso liberador (p.23).

Este tipo de pedagogía funda sus raíces en la teoría crítica que surgió en la Escuela de Frankfurt y Budapest en Europa, hallando uno de sus fundamentos ideológicos en el principio marxista que comprende la necesidad de transformar el mundo y no solo interpretarlo, en consecuencia, esta corriente de pensamiento como lo plantea Maldonado (2011) fue tomando fuerza en contextos geográficos y políticos en tensión, encaminando la reflexión y práctica pedagógica hacia la resistencia y la crítica social.

En ese sentido, la teoría crítica desde el materialismo histórico propone una comprensión particular de la realidad y de la praxis histórica, donde para Kemis \& Carr (1988) la teoría social crítica debe partir de los problemas concretos y vitales de un individuo o grupo social oprimido y alienado, para luego ilustrar a dichos agentes sociales acerca de los factores que le limitan y de los cuales no eran conscientes, al mismo tiempo que les abre un horizonte hacia líneas de acción que les permitirán liberarse, por lo tanto "su meta es el autoconocimiento ilustrado y la acción política eficaz" (p. 169).

Es así como las pedagogías críticas brotan directamente de las ciencias sociales críticas en conformidad con lo planteado en la teoría de las intencionalidades de Habermas, teniendo en cuenta que su propósito es "cuestionar las dependencias ideológicas, fomentar la autonomía e independencia y despojar las ataduras que los sistemas de poder instauran sobre el cuerpo y el alma de los trabajadores. Desde esta perspectiva emerge el interés emancipatorio o de autorreflexión" (Maldonado, 2011, p. 127).

Esta corriente de pensamiento se expande desde Europa y empieza a desarrollarse como hito fundamental de la pedagogía crítica latinoamericana en Brasil, con los planteamientos de Paulo Freire, quien a partir de la lectura social, política y educativa de la realidad brasileña plantea la necesidad de una educación con y desde el oprimido en busca la liberación haciendo uso al mismo tiempo de la hermenéutica, la sociología, la lingüística y el materialismo histórico de tal manera que al igual que la teoría social crítica y la teología de la liberación se preocupa por la praxis y la acción política desde el lugar del pobre y oprimido. Cabe resaltar que este tipo de pedagogía es potenciada y desarrollada en la actualidad por autores norteamericanos como McLaren y Apple y Giroux.

Las características propias de la pedagogía crítica en el continente americano pueden identificarse desde algunos elementos fundamentales, tales como las raíces epistemológicas del movimiento crítico europeo, que son abordadas fuertemente por los norteamericanos y la lectura de la realidad desde una comprensión del materialismo histórico, el proceso de ilustración o concienciación como lo llama Freire, la praxis política del agente social alienado y la liberación.

En este sentido, la realidad desde una perspectiva crítica es comprendida como el conjunto de condiciones sociales, políticas, económicas, educativas, entre otras, dentro de las cuales se encuentra inmerso el sujeto social alienado u oprimido y de la cual no es consciente o lo es muy vagamente. Este elemento es el punto de partida para la pedagogía crítica, debido a que es allí de donde parte la necesidad de liberación entendida como lo plantea Cabaluz (2015) como el conjunto de acciones constantes y transformadoras que humanizan la 
realidad de los oprimidos (p. 81). De igual manera, Ramírez (2008) sostiene que uno de los objetivos de la pedagogía crítica es discernir sobre los imaginarios simbólicos que constriñen a un grupo social; desentrañar sus sentidos y evidenciarlos en la teoría y en la práctica; y reconstruir nuevas formas de interpretar la vida, sociedad, el modo de comportarnos y la forma de interactuar. (p. 112), con lo cual se posibilita el proceso de transformación hacia la liberación.

Por consiguiente, el conocimiento, análisis y conciencia de la realidad se ha de dar dentro de un proceso de ilustración en el cual se identifiquen los problemas, limitaciones y contradicciones sociales presentes en el contexto mediante una dialéctica de problematización.

En este proceso juega un papel fundamental el sujeto alienado, pues la pedagogía crítica reconoce su protagonismo, así como lo anota Freire, (s.f) esta pedagogía debe ser elaborada con el oprimido y no solo para el oprimido, es así como la participación entra también a caracterizar este tipo de pedagogía. Kemmis y Carr (1988) argumentan que el proceso de ilustración debe contar con el discurso práctico de los diferentes participantes, puesto que permite el auténtico entendimiento de la realidad y por ende un acercamiento adecuado y prudente a líneas de acción concretas para la transformación. De la misma manera, Ramírez (2008) propone que la participación fortalece la conciencia de la responsabilidad social con el propio contexto y de la acción democrática para asumir los problemas y proponer soluciones.

Es así, como se logran establecer líneas de acción hacia la transformación de las estructuras sociales opresoras en beneficio de los oprimidos y marginados desde la autonomía y la participación para alcanzar la emancipación, teniendo en cuenta no solo la preocupación "en torno al sujeto, sino también respecto del lugar de influencia en el cual se desarrolla" (Santamaría,
Quitián y Orozco, 2016, p. 218).

En síntesis, como lo argumenta Maldonado (2011) la esencia de la pedagogía crítica se encuentra en la praxis política del oprimido que se libera de las estructuras opresoras de poder partiendo del conocimiento real de su situación de opresión hacia una acción política concreta y construida en participación con otros que se reconocen también en situación de opresión.

\section{De la teología de la liberación y la pedagogía crítica a una fundamentación metodológica}

Hecho el recorrido por algunos de los presupuestos que caracterizan la teología de la liberación y la pedagogía crítica, identificando de manera general sus orígenes, contextos, recorridos y apuestas epistemológicas, resulta evidente reconocer que aunque son dos corrientes surgidas de disciplinas diferentes, pedagogía y teología, cuentan con varios puntos de encuentro, tales como la correspondencia temporal, la influencia de la escuela crítica, el trabajo sobre las categorías de pobre y oprimido, la necesidad surgida de generar agencia entre las personas y el carácter liberador y emancipador que otorgan las ciencias de corte socio-crítico, con ello estas dos corrientes apuntan a fines comunes que se evidencian de sobremanera en el actuar y la responsabilidad política de la liberación.

Dichos fines y elementos en común, permiten a las nuevas elaboraciones teológicas de la liberación recibir aportes de la pedagogía crítica, pues en la teología de la liberación "se debe entender que (...) no es una y única, sino que ella misma está permitiendo diversos caminos y búsquedas que conducen a un único fin, es decir, a la liberación” (Suárez, 2007, p. 170), fin que se comparte, en parte, como ya se había dicho con el objetivo de la pedagogía crítica.

A raíz de las particularidades evidenciadas y los 
puntos de encuentro que se pueden establecer, se aterrizan las apuestas tanto de la teología de la liberación como de la pedagogía crítica en una fundamentación metodológica para la teología de la liberación que se considera, debe tener en cuenta, aportes de la naturaleza epistemológica emanada de la pedagogía crítica, estos aportes, le permitirán a esta fundamentación operar conjuntamente a la teología y a la pedagogía consolidándose como una auténtica oportunidad de liberación y apropiación de procesos emancipatorios enriquecidos por el diálogo de saberes y la experiencia de fe propia de la teología. En esta línea, y aplicado a la comprensión de Ellacuría (1975) se comprende que:

(...) la actividad teológica. Puede y debe incluir, como ya se dijo, una serie de "métodos" parciales o instrumentales: no solo los métodos propios de estudio de la Escritura, la tradición, del magisterio, de la historia del pensamiento teológico, etc; sino también todo el rico instrumental que pueden proporcionar determinados saberes científicos. (p. 620)

En este sentido, resulta enriquecedor el aporte de la pedagogía crítica a la fundamentación de un método de la teología de la liberación, al ser un saber que se aproxima en varios puntos a esta última.

Es así, que bajo este propósito resulta indispensable entender que en este punto al hacer referencia a una fundamentación metodológica, estamos proponiendo unos puntos de referencia que resultan indispensables en la articulación entre estas dos disciplinas y que anteceden la comprensión de un método, entendido este último como "un esquema normativo de operaciones recurrentes y relacionadas entre sí que producen resultados acumulativos y progresivos" (Lonergan, 2006 p. 12), que no se limita a ello sino que con su matiz latinoamericano se comprende como la misma teología en concreto, que demuestra cierta sensibilidad frente a la realidad, y es capaz de hacer preguntas y formular respuestas, encontrando mediaciones que lo complementen (Boff, 1975, p. 131), mediaciones que según Boff (1990) se concentran en tres frentes: la socio-analítica, la hermenéutica y la práctica (p. 101).

En efecto, gracias a la fundamentación propuesta, el resultado metodológico valiéndose de las mediaciones enunciadas, se derivará como consecuencia de sus bases fundamentales y procurará siempre procesos emancipatorios. De esta manera proponemos cuatro características que apoyados con elementos de la pedagogía crítica permiten fundamentar las elaboraciones metodológicas desde la teología alrededor de los fines emancipatorios y de la liberación.

\section{Del conocimiento a la liberación}

Para hablar de una fundamentación metodológica en el plano de la teología de la liberación y apoyada por los aportes de la pedagogía crítica es indispensable tener presente la capacidad cognitiva del ser humano, pues ello deberá considerarse al interior de las posibilidades tanto de aprendizaje, como de formación y de sentido crítico que posibilite rutas de emancipación.

En función del ejercicio del reconocimiento de los fundamentos que operan en el conocimiento, Lonergan (2006) postula en su fundamentación metodológica, unas bases teóricas del conocimiento como elemento esencial de la naturaleza humana, y que responden a la experiencia de comprensión, entendimiento y juicios a través de los sentidos, lo que tanto teórica como prácticamente resulta coherente como base de la capacidad cognoscente del ser humano, donde a partir de lo anterior, y desde esta base para la fundamentación sistemática establece el denominado método trascendental, con la finalidad de proponer un punto de partida único que unifique las 
ciencias, rompiendo con los métodos parcializados por las mismas.

En este orden de ideas, surgidas desde la base de la propuesta de Lonergan, el teólogo Ellacuria (1975) quien soporta sus ideas en las ideas filosóficas de Zubiri plantea que el conocer humano tiene también una inmediata referencia a la praxis, donde necesita como elemento esencial una articulación entre la inteligencia o capacidad cognoscente y la experiencia humana (p. 628), de tal manera que se configura no solo la comprensión, que en términos del autor se corresponde a la inteligencia sentiente, sino también hay un efecto directo de correlación con la praxis humana y la capacidad humana de transformación de su realidad.

Con esta base sobre la importancia del conocimiento humano y su efecto en la praxis desde un campo de comprensión que emana en la teología de la liberación, es oportuno destacar las comprensiones que se dan en razón de esta categoría con énfasis en la mediación otorgada en el escenario de la pedagogía crítica ya que el ser humano conoce y desarrolla variedad de técnicas del aprendizaje en la medida en que se abre a su dimensión social y trascendental, siendo esta un aspecto clave en los procesos de aprendizaje y emancipación, pues como lo afirma Guichot, (2003) haciendo referencia al legado de Paulo Freire, un aspecto particularmente importante en la teoría del conocimiento, es el carácter social que se da en el proceso del saber, teniendo claro que la relación cognoscitiva no concluye en la relación sujeto cognoscente objeto cognoscible, puesto que se extiende a otros sujetos cognoscentes.

Es así que la comunidad de referencia en la que se ubica el sujeto cognoscente, influencia de manera importante las elaboraciones o comprensiones que se deriven en el sujeto, por ello se debe reconocer el papel de la comunidad en la construcción del conocimiento, siendo así el "resultado de la praxis permanente de los seres humanos sobre la realidad" (Guichot, 2003, p. 65).

En efecto, a la luz de dicha comprensión, práctica y social del conocimiento, se establece un avance significativo en los procesos de aprendizaje, los cuales a su vez contribuyen a la formación y transformación del sujeto desde una perspectiva crítica, otorgándole así, la facultad de transformar la comunidad a partir de los procesos de aprendizaje individuales y finalizando con los procesos comunitarios y sociales. De esta manera, no solo se logra imbuir a la comunidad en un sentido cognoscitivo, sino también dignificador y humanizador, en pro de una sociedad en constante proceso de liberación que es un insumo que se reviste de importancia a la hora de pretender fundamentar una metodología que aplique para la teología de la liberación.

\section{Perspectiva de fe y esperanza}

Uno de los motores de la teología cristiana es sin duda la fe ante lo revelado y transmitido por Dios a través de su Hijo y de la comunidad de creyentes, emanando como efecto comprensiones alrededor de la esperanza que configuran la vida del creyente y su responsabilidad ante la humanidad; es bajo esta perspectiva que en el presente apartado se abordará la comprensión de fe y de esperanza como configuradoras de prácticas de emancipación.

De cara a lo anterior, es indispensable iniciar indicando que al interior de la teología el plano de la fe "originariamente es un modo de ser, una actitud fundamental que no se reduce a ninguna otra más originaria y fundamental" (Boff, 975, p. 134), por ello es configuradora de todo lo que marca la experiencia y la interpretación de aquel que cree, implicando consecuentemente una praxis transformadora, generando así que la fe se comprenda también como vivencia.

Bajo este horizonte, "la teología de la liberación parte de la experiencia de la fe que se expresa y 
despliega en dos niveles complementarios e inseparables: el de la praxis y el de la contemplación, el de la espiritualidad y el del compromiso" (Tamayo, 1989 , p. 60), haciendo de la fe una categoría esencial que subyace a la experiencia personal, espiritual y comunitaria, motivando prácticas no solo reflexivas, sino también de carácter práxico.

Es así que esta comprensión de fe, entendida en su carácter práctico y social, está llamada a efectuarse a su vez como un acto de amor y de compromiso, debido a que "la exigencia que la vida de fe debe hacer al creyente, es que su vida sea reflejo de lo que cree, lo que debe llevarlo a un serio compromiso con la historia y con la sociedad en la cual vive." (Suárez, 2007, p. 170).

Compromiso que a su modo es apropiado y vivido por parte de la pedagogía crítica, donde muchas veces al margen de la fe que es el punto de referencia de las elaboraciones teológicas, se vale de la esperanza, la cual entra a ser ese eje motivador para efectuar las acciones comunitarias, esperanza que no pretende "consolar a los oprimidos, sino más bien promover formas duraderas de crítica" (Giroux, 1997, p. 163), a la vez que motiva la promoción de la vida digna y de la emancipación por sobre las estructuras de poder opresoras.

En consecuencia, el ejercicio de la pedagogía crítica de asumir la esperanza como fuerza motivante en oposición a la desesperanza y resignación, demanda por parte de la persona un imperativo ontológico, existencial e histórico (Freire, 1993, p. 24), de tal manera que implique de forma única el actuar en pro de la dimensión personal y comunitaria, pues es algo que en esencia desborda la persona misma y la dispone en función de la comunidad a la que pertenece e impacta. Es así que la esperanza que subyace a la comprensión de la pedagogía crítica dista de la esperanza como categoría teológica pues su origen y su finalidad son diferentes.

De cara a lo anterior, la esperanza abordada desde la pedagogía crítica, resulta como aporte para las elaboraciones teológicas de la liberación y complementaria a la vivencia de la fe, en la medida en que la esperanza comprendida más allá del plano religioso invita a la persona a implicarse en el plano de la existencia tanto personal como comunitaria promoviendo gestos en función de los desarrollos de exámenes críticos de la historia, promoviendo luchas contra la opresión de cara a la liberación, donde, articulado a la vivencia de la fe supone que la experiencia de Dios sea entendida, transmitida y vivida de manera crítica, de tal manera que al ser operativas en la dimensión social promueva actitudes que impacten las realidades tanto personales como sociales en aras de la emancipación, ejerciendo un auténtico papel político motivado por la fe en un Dios liberador y la esperanza que se soporta en el apoyo, compromiso y trabajo con y para los oprimidos, de cara a la promoción del ser humano haciéndole libre.

\section{De la hermenéutica teológica y pedagógica a la responsabilidad socio-crítica}

La hermenéutica surge como disciplina en el estudio de las ciencias sociales como respuesta al positivismo científico y a la búsqueda de un método que permita la comprensión de la historia y la acción humana con toda su carga simbólica, pues como lo indica Ávila, (2007) el ser humano se mueve en ese mundo de símbolos y significados que lo obliga a comprenderlos e interpretarlos permanentemente, teniendo en cuenta que los hechos humanos poseen una significatividad y simbolismo que no poseen otros objetos de estudio puramente científicos y por lo tanto, al margen de las explicaciones, puede estudiarse desde la comprensión entendiendo aquí la hermenéutica como una aproximación "metodológica propia de las ciencias humanas" (Mardones, 1991, p. 31). En ese orden de ideas, la hermenéutica se entiende 
como "el arte y ciencia de interpretar textos, entendiendo por textos aquellos que van más allá de la palabra y el enunciado" (Beuchot, 2009, p. 13), es decir, que incluye la interpretación y comprensión alrededor de acontecimientos históricos, sociales y humanos.

Ahora bien, en este sentido, la teología y la pedagogía pueden encontrar uno de sus fundamentos metodológicos en la hermenéutica, ya que cada una de ellas brota de la reflexión de acontecimientos históricos concretos, que para el caso de la teología de la liberación y la pedagogía crítica latinoamericana parten del contexto histórico latinoamericano con cada uno de sus rasgos característicos de opresión, pobreza e injusticia reflexionados desde el evangelio y la educación respectivamente.

En primer lugar, la teología según Schillebeec$\mathrm{kx}$ se interesa por "actualizar en el presente el sentido de nuestra existencia proclamado ya una vez en la historia" (p. 199). Así, la hermenéutica permite captar la "Vida divina" hablando y comunicándose a la existencia concreta del ser humano, elemento que es ineludible en la trascendencia del hombre que no sólo se encuentra ante su dimensión trascendente sino ante su dimensión histórica y social llamadas a tener un desarrollo armónico entre sí (Boff, 1975, p. 148). De la misma manera Tamayo (2001) plantea la importancia de la "interpretación de los textos fundantes de la fe a la luz de los nuevos contextos socioculturales y de las nuevas experiencias de los cristianos y cristianas, huyendo así de fundamentalismos y de lecturas inmediatistas" (p. 17).

De ahí que por lo que se refiere al método teológico, para Ellacuría (1975) la hermenéutica supone algunas fases tales como "la búsqueda del sentido originario de la afirmación escriturística, su interpretación histórica y desarrollo de sentido en la tradición de la vida y de la doctrina de la Iglesia, y apertura de su significado de salvación a la comprensión del hombre de hoy" (p. 623). Por ello no debe centrarse en aproximaciones dadas por parte grupos elites, sino que debe ser entendida y darle alcance desde las comunidades populares siendo ello una oportunidad de generación de procesos de transformación social y emancipación (Ramírez, 2013)

Por su parte, en el ámbito de la pedagogía crítica, la hermenéutica es entendida desde un aspecto dialéctico en el cual como sostiene Miranda (2006) el sujeto es un individuo histórico capaz de actuar objetiva y concretamente frente a sus relaciones con la naturaleza y los hombres persiguiendo sus fines e intereses dentro de una realidad histórica concreta (p. 102); este actuar concreto, desde la hermenéutica como oportunidad de paso a la responsabilidad socio-crítica debe ayudar a descubrir los sin sentidos de la existencia dentro de la historia, para evitar las tradiciones de opresión y de estructuras de poder represivo y violento (Schillebeeckx, 1973 p.202).

En este sentido para la educación es fundamental partir de la aplicación del círculo hermenéutico de Gadamer desde una relación entre lo general y lo individual, entendiendo lo individual como las comprensiones específicas, que deben tener aplicaciones contextuales y concretas (Beuchot, 2009, p. 10) que para el caso de la pedagogía crítica debe llevar a aplicaciones prácticas de liberación y emancipación de los pobres y oprimidos por medio de la educación.

A su vez Hernández (2001) sostiene que la propuesta concreta es la formación del agente social desde la hermenéutica a través de la cual sea capaz de interpretar el mundo semiótico que le rodea, lo oprime, le lanza propuestas, buscando así generar posturas críticas ante las estructuras de opresión que le mantiene como sujeto pasivo y acrítico. En este mismo sentido, la hermenéutica por medio de los procesos pedagógicos exige diálogo y participación de y entre los sujetos alienados, de tal 
manera que se den transformaciones en las expectativas y las acciones.

De esta manera, como se puede apreciar tanto en la pedagogía como en la teología, la hermenéutica juega un papel fundamental, pues es la que permite entender e interpretar las realidades circundantes, donde a partir de este entender e interpretar se promueve el actuar de corte sociocrítico. La diferencia fundamental entre estas dos comprensiones y aplicaciones de la hermenéutica radica en que para la pedagogía la vía por excelencia de formación de pensamiento crítico es la educación, mientras que para la teología es la interpretación fundamentada en la experiencia de fe, lo que supone que al articular las dos perspectivas en pro de una fundamentación metodológica para la teología de la liberación de como resultado una formación en pensamiento crítico que sirva para concientizar al sujeto de su situación de opresión, valiéndose de mediaciones otorgadas gracias a los contextos pedagógicos abordando e interpretando la realidad desde la experiencia continua de fe.

\section{Los signos de los tiempos y la praxis histórica como fuente de la liberación}

A partir del Concilio Vaticano II en la Constitución Pastoral Gaudium et Spes se propone como “(...) deber permanente de la Iglesia escrutar a fondo los signos de los tiempos e interpretarlos a la luz del Evangelio" (GS 4), ello se comprende como la labor misionera de la Iglesia que se desarrolla ad extra, donde se reconoce también allí la manifestación del reino (Azcuy, 2014, p. 331), invitando así a interpelar, evaluar y reconocer en los hechos y acciones de los tiempos siempre el actuar de Dios y por ende la pertinencia del actuar eclesial.

De cara a lo anterior, para una fundamentación metodológica de la teología de la liberación, la lectura de los signos de los tiempos es indispensable debido a que marca una manera única de entender y reinterpretar las tradiciones teológicas pre y pos conciliares a la luz de las lecturas de las realidades y necesidades actuales evidenciado ello en las nuevas perspectivas de trabajo pastoral y eclesial, invitando a la transformación del quehacer y fundamentar teológico, que tiene como elemento central la reflexión en torno a la experiencia de fe y la praxis eclesial, alrededor del diseño del Reino de Dios en la historia inscribiéndose allí el fenómeno mismo de la revelación, principio primero de la teología (Parra, 2013, p. 143).

En este ejercicio de transformación, la Iglesia Latinoamericana a través de las Conferencias Generales del Episcopado Latinoamericano y del Caribe y la comunidad de teólogos y académicos, han marcado un horizonte de comprensión del ejercicio misional de la Iglesia y de la Teología a la luz del Concilio y de las realidades propias del continente, matizando con ello un movimiento denominado teología de la liberación, el cual a través de sus desarrollos históricos "ha sido abordado de manera creativa y original a partir de la nueva experiencia y conciencia eclesial latinoamericana (...) que acentúa la dimensión histórica, comunitaria y fraterna de la Iglesia, así como su función evangelizadora al servicio de la liberación de los oprimidos" (Tamayo, 1989, p.120).

Bajo lo anterior resulta oportuno tenerse en consideración que al interior de la teología de la liberación y del actuar eclesial es fundamental el hecho de la conciencia histórica a la que se procura una "(...) búsqueda de una nueva y más intensa presencia de la Iglesia en la actual transformación de América Latina" (Medellín, 1968, introducción, 8). Presencia que trasciende el plano reflexivo y se concretiza en la praxis eclesial y teológica procurando la transformación de un modo efectivo y articulado a la actualidad de las circunstancias sociales (Schillebeeckx, 1973, p. 188), para ello es clave la comprensión de una teología que ya no 
estará "en defensa de la dominación, ni siquiera en defensa de los intereses institucionales de la Iglesia, sino una teología que vive de las mismas fuentes de la fe" (Tamayo, 1989, p. 34).

De esta manera, la teología "que no sea elaborada en y desde la praxis no es teología, por lo menos como se entiende en la teología de la liberación" (Suárez, 2007, p. 168), de manera tal que "la praxis sería el 'acto primero', mientras que la teoría, incluyendo la teoría teológica, sería 'acto segundo' " (Parra, A. 2013, p. 150) y todo ello teniendo en cuenta siempre las concreciones y desarrollos históricos del ser humano en sus distintos contextos.

En este sentido, se hace menester descubrir el auténtico papel de la Iglesia, el cual no sólo es el de anunciar históricamente la salvación, sino que debe buscar realizarla también históricamente (Ellacuria, 1984, p. 220), por ello es importante que los presupuestos eclesiales deban estar en posibilidad de identificar corrientes teológicas desarrolladas históricamente que macarán el actuar más próximo a la liberación, logrando con ello que las nuevas reflexiones orienten y acompañen las nuevas prácticas eclesiales en pro de la liberación, pues "sólo una Iglesia operante en la historia puede descubrirnos y comunicarnos efectivamente al Dios de la historia, al Dios históricamente dado; sólo en la historia encontrará la Iglesia el campo adecuado para realizar y hacer creíble su misión" (Ellacuria, 1984, p. 225).

Por su parte la pedagogía crítica de similar manera como la teología de la liberación se comprende como "una política de comprensión, un acto de conocimiento que intenta situar la vida cotidiana en un contexto geopolítico más amplio, con el objetivo de fomentar un colectivo regional de auto-responsabilidad, ecumenismo a gran escala y solidaridad obrera internacional" (MacLaren, 2006, p. 328), teniendo como centro el sujeto no entendido de manera individual sino como parte de un colectivo, que va mucho más allá de la ilustración personal, en procura de "la acción social colectiva conectada profundamente con los ideales emancipadores de la racionalidad, la justicia y la libertad" (Carr, 1999 p. 31).

En esta acción social se descubre que en las lecturas de la realidad se puede identificar no solo como necesitado de liberación el oprimido tradicionalmente entendido, ello lo evidencia claramente el brasileño Paulo Freire quien sostiene que la tarea humanística e histórica de los oprimidos es liberarse a sí mismos y liberar a los opresores, debido a que estos oprimen, explotan y violentan es en razón de su poder, lo que los convierte en opresores oprimidos (Freire s.f. p. 23), es por ello que al hablar de liberación la pedagogía crítica propuesta en Freire se debe entender también en razón del opresor.

Es así que "cuando Freire hace mención del contexto de deshumanización en el que se da la contradicción principal entre Opresor-Oprimido, está planteando que tanto en los despojados como en los que despojan se da una condición de pérdida de humanidad" (López, 2004, p. 42), por ello la labor educativa de liberación debe ir en doble vía, es decir hacia el oprimido y hacia el opresor en búsqueda de la emancipación para ambos que en últimos términos son todos oprimidos, y estos naturalmente no se pueden entender sin los contextos a los que pertenecen pues "la cultura es uno de los anclajes que nos sitúan en el mundo, gracias al cual éste adquiere un determinado sentido para nosotros. La manera de entender cómo se lleva a cabo ese amarre a través de la cultura es fundamental para la educación (Sacristan, 2002, p. 22).

Con lo anterior se puede extraer una categoría de abordaje que la labor teológica de la liberación y una fundamentación metodológica debe tener en cuenta, y es el de la opresión en doble vía, es decir efectuada sobre el oprimido y sobre el opresor, para que así en las elaboraciones teológicas se tenga en cuenta que la finalidad emancipadora 
aunque está centrada en el pobre, se debe entender que aquel no es pobre en sentido único, sino que hay un pobre que ejerce labores de opresión y sobre él debe trabajar también la teología buscando reconocer ese ser como oprimido también y así dimensionar y focalizar la práctica teológica a la liberación de opresor y oprimido.

En síntesis, del presente apartado, es importante tener presente la advertencia hecha por Schillebeeckx (1973) sobre el peligro de toda ciencia crítica de desvirtuar su carácter en la medida que olvide su dimensión práctica, es por ello importante tener en cuenta que tanto para la teoría como para la reflexión que se encaminan esencialmente hacia la liberación del hombre debe haber una fuerza emancipadora fundamentada en la autorreflexión, conocimiento e interés.

\section{Conclusiones}

Muchos de los teólogos actuales se han interesado en presentar una nueva perspectiva de la teología, enfocándola desde el aspecto contextual y liberador; dicha reflexión ha tenido lugar en el contexto latinoamericano hacia la década de los 60 's, como una reflexión crítica de la praxis histórica, la cual se fundamenta en un proceso liberador que irrumpe en la realidad a la luz de la fe y la praxis evangélica desde los numerosos contextos de opresión y marginación. Muestra de este análisis ha quedado manifiesto en páginas anteriores, como resultado del estudio y reflexión sobre el pensamiento de los teólogos y pedagogos abordados en dicho proceso de investigación.

Es de tener presente que la teología de la liberación ha pasado por diversas etapas, en las cuales se han cuestionado aspectos tales como, la manera en la cual la Iglesia manifiesta su presencia en el continente latinoamericano y el impacto transformador del anuncio evangélico, razón por la que el concilio vaticano II y la Conferencia
General del Episcopado Latinoamericano y del Caribe, celebrada en Medellín (1968), analizaron y evaluaron dicha misión evangelizadora en todos los ámbitos pastorales.

Al enfatizar en aspectos claves de evangelización, entra a colación una introspección sobre la fe, pues es la que lleva al teólogo a hacer teología como una forma de proclamar y vivir el Evangelio desde la percepción histórica de la realidad de pobreza y opresión, la cual está acompañada por un carácter dialéctico y político; razón por la cual, el objetivo planteado por la Teología de la liberación da lugar a la restauración y dignificación de la vida humana.

Paralelamente a la Teología de la Liberación surge una pedagogía de carácter crítico, fruto de la lectura de los contextos y sus problemas sociales, educativos, políticos y económicos dominantes, la cual recibe notable influjo de las ideas marxistas conexas con la lucha de clases y la emancipación, que no obstante no se reduce a ello pues no busca ser totalizante y ha ampliado notablemente su campo de acción, discurso y repercusiones de corte práctico. Sumado a ello, es necesario precisar que uno de los objetivos de la pedagogía crítica es comprender los imaginarios simbólicos que violentan y oprimen a un grupo social, puesto que el conocimiento y el poder de la educación es el que posibilita el proceso de transformación hacia la liberación. Razón por la cual, esta pedagogía debe ser elaborada con el oprimido y no sólo para el oprimido, contando a la vez con la participación de otros sujetos dominados que enriquecen el proceso de concienciación o ilustración de las condiciones y situaciones de opresión, encontrando así la esencia de la pedagogía crítica en la praxis política del oprimido el cual se libera de las estructuras opresoras de poder.

Estamos, por tanto, frente a una caracterización de la teología de la liberación y la pedagogía crítica, donde se han asemejado en cuestiones de 
orígenes, contextos, recorridos y apuestas epistemológicas, en las que se resaltan las convergencias evidenciadas en los sujetos, el actuar y la responsabilidad política de la liberación.

Es bajo este pretexto, que el presente artículo busca desarrollar una fundamentación metodológica, que a la vez que se vale de los elementos en común, articule estas dos disciplinas, y las complemente a partir de las divergencias, en procura de desarrollos teológicos que estén promovidos e impulsados por los aportes de la pedagogía crítica.

Es en este proceso, donde se considera como fundamental los desarrollos a partir 4 categorías que se consideran esenciales, estas son:

Del conocimiento a la liberación, la cual se vale de los procesos de aprendizaje, con la finalidad de aportar a la formación y transformación del sujeto desde una perspectiva crítica, haciendo usos de la facultad de transformación de la comunidad a partir de los métodos de aprendizaje individuales y comunitarios.

La perspectiva de fe y esperanza, donde la fe se convierte en el punto de referencia de las elaboraciones teológicas, valiéndose de la esperanza entendida en sentido pedagógico, como pauta esencial de la motivación en la proyección de las acciones de carácter social y comunitario.

De la hermenéutica teológica y pedagógica a la responsabilidad socio-crítica, la cual ilumina la historia desde la lectura del evangelio y de fe del sujeto, a la vez que reconoce su capacidad de descubrir los sinsentidos de la existencia humana presentes en la historia para luchar contra las estructuras de opresión desde los distintos escenarios.

Finalmente se presenta una categoría sobre los signos de los tiempos y la praxis histórica como fuente de la liberación, la cual sitúa desde un escenario de comprensión histórica, el actuar misionero de la Iglesia, articulando, entendiendo e interpretando la condición de pérdida de humanidad a la luz de la labor educativa, en la cual la liberación se enfoca desde el carácter emancipador de corte intelectual y social en doble vía, tanto del oprimido como del opresor.

\section{Referencias}

Alutíz, J. (2010) El paradigma comunicativo de Jürgen Habermas para las ciencias sociales. Revista Española de sociología, (13), 81-105.

Ávila, R. (2007) Fundamentos de pedagogía. Hacia una comprensión del saber pedagógico. Bogotá: Colección Seminarium MAGISTERIO.

Azcuy, Virginia R. (2014). La manifestación salvífica de Dios y su discernimiento en los signos de los tiempos: El giro soteriológico-pastoral en el Concilio Vaticano II. Teología y vida, 55(2).

Beuchot, Mauricio. (2013). Hermenéutica analógica, Filosofía de la religión y teología fundamental. Bogotá: Ediciones USTA.

Boff, L. (1975) ¿Qué es hacer teología desde América Latina? En Dussel, E. et al. Liberación y Cautiverio. Debates en torno al método de la teología en América Latina. México, D.F. 129-154.

Boff, 1. (1984) Teología desde el lugar del pobre. Bilbao: Editorial Sal Terrae.

Cabaluz, F. (2015). Entramando pedagogía críticas latinoamericanas: notas teóricas para potenciar el trabajo político-pedagógico comunitario. Santiago de Chile: Editorial Quimantú.

Carr, W. (1999). Una teoría para la educación. Hacia una investigación educativa crítica. Madrid: Ediciones Morata.

CELAM. (1968). Medellín: conclusiones II Conferencia General del Episcopado Latinoamericano.

Boff, C. (1990) Epistemología y método de la teología de la liberación. En Ellacuria, I. (Ed), Mysterium Liberationis. Conceptos fundamentales de la teología de la liberación. Madrid: Trotta.

Concilio Vaticano II. (1965). Constitución Pastoral «Gaudium et Spes» sobre la Iglesia en el mundo 
de hoy.

Ellacuria, I. (1984) Conversión de la Iglesia al Reino de Dios. Para anunciarlo y realizarlo en la historia. Santander: Sal Terrae.

Ellacuria,I.(1975).Haciaunafundamentaciónfilosófica del método teológico latinoamericano. en Dussel, E. et al. Liberación y Cautiverio. Debates en torno al método de la teología en América Latina. México, D.F. 609-637.

Freire, P. (1993) Pedagogía de la esperanza, un reencuentro con la pedagogía del oprimido. México D.F.: Siglo XXI editores. Novena Edición.

Freire P. (s.f.) Pedagogía del oprimido. Recuperado de http://www.servicioskoinonia.org/biblioteca/general/FreirePedagogiadelOprimido.pd

Giroux, H. (1997). Los profesores como intelectuales hacia una pedagogía crítica del aprendizaje. Madrid: Paidós. Séptima impresión, primera reimpresión.

Gutiérrez, G. (1975). Teología de la liberación. Perspectivas. Salamanca:Sígueme.

Kemmis, S. \& Carr, W. (1988) Teoría crítica de la enseñanza. España: Martínez Roca

Lonergan, B. (2006) Método en teología. Salamanca: Ediciones sígueme.

López, C. (2004) Proceso de reflexión colectiva sobre la vigencia y desafíos de la Educación Popular. En Consejo de educación de adultos de América Latina. Debate Latinoamericano sobre Educación Popular II. México D.F.: CEAAL.

Maldonado, M. (2011). Pedagogías críticas. Europa, América Latina, Norteamérica. Bogotá: Editorial Magisterio.

McLaren, P. (2006). La enseñanza contra el capitalismo global y el nuevo imperialismo. Una pedagogía crítica. Madrid: Popular.

Parra, A. (2013). De camino a la teología de la acción. Theologica Xaveriana, 62, (174).

Ramírez, F. (2013). La lectura popular y comunitaria de la biblia como didáctica de la Fe en contextos Latinoamericanos. Revista Albertus Magnus, 4 (2), 211-219.

Ramírez, R. (2008). La pedagogía crítica. Una manera ética de generar procesos educativos. Folios: segunda época, (28), 108-119

Sacristan, J. (2002). Educar y convivir en la cultura global. Las exigencias de la ciudadanía. Madrid: Ediciones Morata.

Santamaría, J., Quitián, E. \& Orozco, L. (2016). Caracterización de una pedagogía de la teología en perspectiva crítico-liberadora. Reflexiones desde la pedagogía crítica y la teología de la liberación. Revista Albertus Magnus, (7,2), 213-237.

Schillebeeckx, E. (1973). Interpretación de la fe. Aportaciones a una teología hermenéutica y crítica. Salamanca: Sígueme.

Sobrino, J. (2001). Teología desde la realidad. En J.J. Tamayo. \& Bosh, J. (Eds.), Panorama de la Teología Latinoamericana. 301-315. Navarra: Verbo Divino.

Suárez, G. (2007). El método de la Teología de la Liberación. en Baena, G. et al. Los métodos en teología. Bogotá: Pontificia Universidad Javeriana. 157-185.

Tamayo, J. J. (2001). Cambio de paradigma teológico en América Latina. En J. J. Tamayo, \& J. Bosh (Eds.). Panorama de la Teología Latinoamericana. Navarra: Verbo Divino, 11-52).

Tamayo, J. (1989). Para comprender la teología de la liberación. Estella: Verbo Divino. 